\title{
Impacts of technological advancements on consumer's decision-making and behavior in the fashion retail industry
}

\section{Introduction}

My professional career as a professor in the higher education has been only fourteen years yet my scholarly research endeavor had started as a Ph.D. student at Iowa State. My seminal work has been heavily benefited from healthy debates and collaboration with a number of wonderful colleagues and I sincerely note their great inspiration and strong friendship for all those years. In this opinion piece, I would like to discuss the empirical findings that my colleagues and I have discovered to provide additional new knowledge to the field of Clothing and Textiles around the unifying theme of advanced technology and its impact in the fashion industry especially the retail environment as communication, promotional, and transaction platform between business and end-users/consumers. ${ }^{1,2}$

From the beginning human psychology has been the fascinating subject matter to me. My colleagues and I have examined various consumer socio-psychological variables to deepen the understanding on consumer behavior in the ever-changing retail environment-for instance, perceptions of value and quality with Mary Lynn Dam horst, my dissertation advisor; ${ }^{3}$ shopping orientations with HyunHwa Lee and Ann Marie Fiore; self-monitoring tendency and fashion involvement with Kim Hahn to name a few. This opinion piece is organized by the themes: Electronic commerce, image interactivity technology, wait time in online apparel shopping, multichannel retailing, mobile communication and commerce, and VR and AR for the retail industry.

\section{Electronic commerce (2000-20 I 2)}

During the mid 1990s we experienced the birth of the e-commerce and it brought plethora of debate and predictions on how the e-commerce will change the retail landscape. It certainly provided fashion retailers with mail-order catalogs as promotional and transactional channel a huge leg up (e.g., J. Crew, Lands' End, Victoria's Secret).

During the turn of the 21 st century, we experienced the dotcom burst and only the truly viable e-commerce business survived from the storm. It was a tough reality check on the positive and hopeful predictions toward the e-commerce for both $\mathrm{B} 2 \mathrm{~B}$ and $\mathrm{B} 2 \mathrm{C}$. After the dotcom burst, apparel and accessories ranked as the third best-selling product category in B2C e-commerce sales. ${ }^{4,5}$ One of the very first researches was completed by E Yoh. ${ }^{1}$ From a random national survey, she found that consumers would be more willing to adopt the Internet shopping for apparel if there are market incentives such as free and convenient returns, innovative product presentation, and credit card security. She also noted that prior experience with the Internet was the strongest predictor of one's adoption of the Internet for apparel shopping.

Her research truly inspired me to decide to come pursue my doctoral degree at the institution. Following the great footsteps of the research effort of Yoh and her colleagues, Jihye Park and I invested how the consumer's attitude toward a fashion brand would influence
Volume 3 Issue $3-2017$

\author{
Jihyun Kim \\ Faculty Director of the Fashion School Store, College of the \\ Arts, Kent State University, USA
}

\begin{abstract}
Correspondence: Jihyun Kim, Ph.D,Associate Professor and Faculty Director of the Fashion School store, The Fashion School, College of the Arts, Kent State University, P.O. Box 5190 , 515 Hilltop Drive, 2 18-B Rockwell Hall, Kent, $\mathrm{OH} 44242-0001$, USA, Tel I330672 |473, Fax 13306723772, Email jkim55@kent.edu
\end{abstract}

Received: November 06, 2017 | Published: November 22, 2017

their attitude toward the online channel of that fashion brand. ${ }^{6}$ In this particular study, we discovered that consumer's attitude shift was occurred from the brick and mortar retail channel to online channel. For instance, consumer's perception of their control and capacity toward a shopping online and their intention to search apparel product information via online channel boosted the consumer's purchase intention via the online channel. With this study, we added an empirical support on the effectiveness of online business entry strategy to the existing fashion brands. In addition, we highlighted the importance of level of information delivered via e-commerce site can be a very crucial factor determining one's online purchase behavior. ${ }^{6}$

\section{Image interactivity technology (2005-2010)}

Another crucial aspect of the online apparel shopping has been the hedonic benefits. With a great influence by Ann Marie Fiore and other colleagues, I have investigated the hedonic impact of the interactive online features on apparel retail website. For instance, a study by Fiore, Jin \& $\mathrm{Kim}^{2}$ found that individual's optimal stimulation level influenced one's recreational shopping tendency and trying image interactivity on the apparel retailer site, which in turn, resulted in higher emotional arousal and emotional pleasure as responses. Another seminal work with Fiore and Lee, we found that 3-D virtual trying-on model as an image interactivity technology (IIT) feature on apparel retailer website supported the notion of fun/pleasure related aspects could increase one's sense of being on the shopping retailer site being more pleasant ("telepresence"), perception of both instrumental and experiential values. ${ }^{7}$ In another study, this triad research team provided important theoretical support on the application of Technology Acceptance Model in the ecommerce setting using the ITT. ${ }^{8}$ In third piece of this triadic team effort, we found that ITT was a successful variable to predict consumer's online retailer patronage behavior through enhanced store perception, enhanced shopping enjoyment and involvement, in turn; they wanted to stay longer at the online store and willing to return and shop again from the retailer. ${ }^{9}$ 


\section{Wait time in online apparel shopping (200I-2007)}

In addition to all the fun and experiential factors involved online apparel shopping, there were some concerns and downsides to the consumers such as lacking of trying on opportunities and delay in receiving and consuming the product ordered online. In an experimental study, Park and I highlighted one of two critical barriers of online apparel shopping, which we referred as perceived consumption delay. ${ }^{10}$ Due to the relatively short life cycle that fashion products yield, consumers would be sensitive to the consumption delay as well as they may perceive higher risk in relation to time which happens when one is shopping over the Internet or mail-order catalog (even though during the 2000s, many consumers have already adopted the Internet to complete their order of the products seen in the mail-order catalog). Consumer's perceptions of risk involved in time related factors (in other words delivery time due to the perishability of the nature of the fashion product) and delay involved in receiving and wearing (consuming) the fashion products purchased online, resulted in negative evaluation of the apparel website. And in turn, these factors influence negatively on purchase intention of via online fashion retailer site ${ }^{10}$ which were in line with previous findings in other settings Hui et al. ${ }^{11}$ Taylor. ${ }^{12}$ With the findings, we argued that online apparel retailer should pay close attention to inventory control, order fulfillment, and service recovery when the consumer expectation is not met. In addition, we also stressed that online apparel retailer should clearly communicate what the consumer should expect regarding the delivery time and possibly update the consumers with the process of fulfillment via email.

\section{Multichannel retailing (2000-20 I4)}

E-commerce research has a slight pivot toward the multichannel retailing during the 2000 s in order to full capturing the impacts of the Internet as transactional channel in the retail industry. My research journey on the broad topic of multichannel retailing started when I was a doctoral student at Iowa State. Hyun-Hwa Lee and I were overlapped about three years in the Ph.D. course work and we naturally shared similar interests on the topic. Early of the MCR studies investigated the individual consumer's various channel usages based on perceived retail usefulness and consumer's orientation and their satisfaction with various retail channels. ${ }^{13}$ Another study examined how consumers are transferring their attitudes and behavior in relation to the online apparel retailer to the gift-giving context. ${ }^{14}$ Later another research articulated the great needs of cross-channel integration strategies and measuring its effectiveness such as consistency in retail policy, product/assortments, price, and promotional efforts throughout the various channels operated by multi-channel retailers. ${ }^{15}$ After the economic recession started in 2008, the importance of understanding the consumer psychology behind patronizing the multichannel mass merchants such as Wal-Mart and Target, to name a few. Thus, in another study the antecedents and consequences of multichannel shopping value of mass merchant were investigated to highlight the key impact that value perception contributes to the MCR industry. ${ }^{16}$

\section{Mobile communication and commerce (2009-20 I7)}

Some of the research endeavor within the realm of e-commerce also highlighted the imperativeness of the mobile device as the gateway for communication and commerce. Earliest work shed lights on the matter of consumer adoption of mobile technology for fashion products in collaboration with Maand Park ${ }^{17}$ using the combined theoretical framework based on Technology Acceptance Model and Theory of Reasoned Action. Due to the public visibility of the use of mobile device, subjective norm was quite crucial factor to predict the consumer's attitude toward the mobile communication and in turn, attitude toward the mobile-commerce for fashion products. This piece was noted as one of the earliest attempt to understand fashion consumers' adoption of the mobile technology. In the subsequent effort in this topic, Lee and $\mathrm{I}^{18}$ provided a conceptual framework called mobile channel extension model providing the empirical support on the effects of compatibility of the channel and media influence on mobile use as the additional predictor of the consumer's attitude and behavior intention in relation to mobile shopping. More recent body of research in collaboration with Kim Hahn has focused on the individual consumer's innate personal trait variables such as high tech involvement, proclivity to experiment, fashion involvement, ${ }^{19}$ selfmoniotring tendency ${ }^{20}$ and peer influences ${ }^{21}$ on mobile technology adoption for communication and commerce. Another study we compared the fashion major students against non-fashion students and found empirical findings to support the old notion of self-monitoring tendency, fashion involvement, and proclivity to experience with appearance that was believed without the test results. In addition, we found that fashion major students exhibited significantly higher score on mobile dependency in comparison to the counterparts, which added additional support to the application of extended self-concept to the mobile technology adoption literature. Most recent piece examined the consumer's evaluative criteria of the mobile phone case evaluative criteria and revealed that heavily dependent mobile users rated higher importance of aesthetics, brand, expressiveness of individuality, and functionality of the mobile case, comparing to the counterpart. ${ }^{22}$

\section{VR and $A R$ for the retail industry}

Recently, Google Pixel 2 phone has been launched and it runs the cooperative advertising promotion with Verizon at the moment. Even though the mobile device market shares of the Google Pixel's first generation phone did not meet the firm's expectation; yet Tango AR platform by Google has been applied to the retail industry for furniture sector such as Pottery Barn, Wayfair, Lowe's and Houzz. Initially, this Tango AR platform was only available to the Google Pixel phone. Lately, Google ARCore technology allows the Android users augmented reality without Tango, for instance, Asus Zen Fone AR in mid-August in 2017. Google's ARCore is similar to the Apple's ARKit. With all the advancement in the mobile technology especially $\mathrm{AR}$, the future of the retail industry triggers a lot of the healthy debates and predictions for the consumer adoptions of its technology. Even though this AR technology is, at the moment, mainly geared toward the furniture sector of the retail industry; yet, I would carefully anticipate the diffusion of such technology to the fashion retail industry. Having said that, the marketers and researchers/educators have a lot of new discoveries to do in the possibility around this topic in the context of the Fourth Industrial Revolution.

\section{Acknowledgements}

None.

\section{Conflict of interest}

Author declares there is no conflict of interest in publishing the article. 


\section{References}

1. Yoh E. Consumer adoption of the Internet apparel shopping. Iowa State University, Ames, USA; 1999. p. 1-143.

2. Fiore AM, Jin HJ, Kim J. For fun and profit: Hedonic value from Image interactivity and responses towards an online store. Psychology \& Marketing. 2005;22(8):669-694.

3. Kim J. Effects of perceived merchandise quality and service quality on consumer shopping behavior in the Internet apparel retailing environment. Iowa State University, Ames, USA; 2004. p. 1-190.

4. Forrester Research. Q2 Online sales: Same (old) growth story. 2003.

5. US online consumer sales surge to \$53 billion in 2001. 2002.

6. Kim J, Park J. A consumer shopping channel extension model: Attitude shift toward the online retailer. J Fashion Marketing \& Management. 2005;9(1):106-121.

7. Fiore AM, Kim J, Lee HH. Effect of image interactivity technology on consumer responses towards an online retailer. $J$ Interactive Marketing. 2005;19(3):38-53.

8. Lee HH, Fiore AM, Kim J. The role of the technology acceptance model in explaining effects of image interactivity technology on consumer responses. International J Retail \& Distribution Management. 2006;34(8):621-644.

9. Kim J, Fiore AM, Lee HH. Influences of online store perception, shopping enjoyment, and shopping involvement on consumer patronage behavior towards an online retailer. $J$ Retailing \& Consumer Services. 2007;14(2):95-107.

10. Park J, Kim J. The importance of perceived consumption delay in Internet shopping: Time-related information, time risk, attitude, and purchase intention. Clothing \& Textiles Research J. 2007;25(1):24-41.

11. Hui MK, Thakor MV, Gill R. The effect of delay type and service stage on consumers' reactions to waiting. J Consumer Research. 1998;24(4):469-479.

12. Taylor S. Waiting for service: The relation- ship between delays and evaluations of service. $J$ Marketing. 1994;58(2):56-69.
13. Lee HH, Kim J. The effects of shopping orientations on consumer satisfaction toward product search and purchases in a multi-channel environment. J Fashion Marketing \& Management. 2008;12(2):193-216.

14. Lee HH, Kim J. Gift shopping behavior in a multichannel retail environment: The role of personal purchase experiences. International $J$ of Retail and Distribution Management. 2009;37(5):420-439.

15. Lee HH, Kim J. Investigating dimensionality of multichannel retailer's cross-channel integration practices and effectiveness: Shopping orientation and loyalty intention. J Marketing Channels. 2010;17(4):281-312.

16. Kim J, Lee HH. I love the value of shopping at mass merchants! Consequences of multichannel shopping value. J Marketing Channels. 2014;21(1):18-30.

17. Kim J, Ma YJ, Park J. Are US consumers ready to adopt mobile technology for fashion goods? An integrated theoretical approach. J Fashion Marketing \& Management. 2009;13(2):215-230.

18. Kim J, Hahn KHY. Effects of personal traits on Generation Y consumers' attitudes toward the use of mobile devices for communication and commerce. Human Technology: An Interdisciplinary J on Humans in ICT Environments. 2012;8(2):133-156.

19. Lee HH, Kim J. Toward developing a mobile channel extension model: Roles of compatibility, subjective norm, and media influences. $J$ Korean Society of Clothing \& Textiles. 2011;35(12):1425-1439.

20. Kim J, Hahn KH. The effects of self-monitoring tendency on young adult consumers' mobile dependency. Computers in Human Behavior. 2015;50:169-176.

21. Hahn KHY, Kim J. Salient antecedents of mobile shopping intentions: Media dependency, fashion leadership, and peer influences. J Global Fashion Marketing. 2013;4(4):225-246.

22. Hahn KHY, Kim J. Understanding toward mobile phone case evaluative criteria among US millennials: Aesthetics, brand logo, individuality expression, expression of interests, and functionality. International $J$ Fashion Design, Technology \& Education. 2016;9(1):23-31. 